\title{
Early Challenges and Successes from Adapting the Laboratory Model to Undergraduate Teaching Institutions ${ }^{1}$ \\ Kelly Bauer, Nebraska Wesleyan University ${ }^{2}$
}

As the laboratory model is becoming increasingly popular in Political Science, what are the best models of adapting this research opportunity to an undergraduate teaching institution? Undergraduate research experiences are a high impact learning practice, but access to these opportunities are often limited. New research documents how innovative adaptations of the laboratory model to the social sciences offers students valuable scaffolded research training and mentoring (Becker 2019). How can this model be adjusted to smaller teaching institutions, where funding, research time, and student-led research mentoring are often more limited? This paper documents successes and failures from a collaborative research initiative on immigration politics in Nebraska started in August 2019 at Nebraska Wesleyan University, through which students wrote and presented and presented one paper, and co-designed a second project for the spring 2020 semester. This paper documents student learning outcomes and scalability challenges and opportunities, focusing on early challenges and successes in hopes of assisting other faculty interested in expanding this research opportunity most efficiently and effectively.

\section{Promise and Limitations of Undergraduate Research Experiences}

AACU work on High Impact Practices (HIPs) documents that undergraduate research experiences are a high impact learning practice. But, access to these research experiences are is not equally accessible for all students, and the significance of the learning experience for students is often limited by the direction of the research. If these research experiences occur outside of the classroom, they are often faculty-driven, with faculty creating create research opportunities that most efficiently advance their research. If these research experiences occur inside a classroom, they are often student-driven, which are labor intensive for faculty advising work outside of their areas of expertise

${ }^{1}$ Prepared for presentation at the American Political Science Association Teaching and Learning Conference in Albuquerque, New Mexico, February 7-9, 2020. Please do not cite without the authors' explicit permission.

2 kbauer@nebrwesleyan.edu 
(Buddie and Collins 2011). In both cases, access to undergraduate research experiences is very structured by students' ability, time, advising, awareness of, and access to the structures through which these experiences are structured on campus.

In Political Science, scholarship has found that the experience is impactful, with most of the conversation centered around how curriculum formalizes students training in research methodology courses, and experiences in senior capstone projects (Ishiyama and Breuning 2003, Ishiyama 2019). How can faculty create more broader and deeper access to undergraduate research opportunities? What would opportunities look like for students who are less prepared for, but ambitious about pursuing research? How could students with less preparation have more access to research opportunities? Megan Becker (2019) has recently called for pulling these experiences outside of the classroom, adopting the scaffolded model of training and mentoring found in science labs; in this paper, I document my own reflections and work to do this work by importing the lab model into the social sciences at my own liberal arts university.

In thinking through how to deepen and broaden access to undergraduate research opportunities, this project adopts the Students as Partners approach to teaching and learning. This philosophy calls on students to play active roles in their learning by serving as co-creators of knowledge (Cook-Sather, Bovill, and Felten 2014). To this end, I formed a student-faculty collaborative research initiative, Study of Immigration Politics in Nebraska (SIPN), in August 2019 to experiment with adapting the lab model to a liberal arts setting.

\section{Semester 1: Experimenting}

I recruited three women to be SIPN scholars for the first semester of work. Selected for their interest and/or familiarity with local immigration politics, scholars independently and collaboratively researched immigration politics in Nebraska. Our collaborative paper, "Surpassing the Wall of Nebraska Nice: An analysis of trends and justifications of immigration rhetoric within Nebraska journalism," was presented at the North Central Council of Latin Americanists annual meeting in October 2019. The 3 scholars were awarded a travel grant to support their participation and scholarship, and our research was recognized with the conference's Collaborative Research Award. This work was based on our analysis of 100 news articles covering of immigration politics in Nebraska from September 2017-September 2019, and we found that national conversations about the 
rhetoric surrounding immigrants and immigration policy do not fully explain how these conversations happen in Nebraska.

To get to this point, our team met once per week. During that meeting, we worked through stages of the research process, with each member taking on a responsibility of work to prepare for the following week. In addition to the research process represented by the final paper, we also worked through grant writing and preparing for an academic conference. While I set the initial list of tasks and estimated a timeline to ensure we would be ready for the conference, the timeline and writing was collaborative.

\section{Semester 2: Scaling}

During the spring 2020, I am expanding the work to create mentoring roles, while keeping the research collaborative. Two of the students from fall 2019 are remaining on the team (the third is studying abroad and frequently asks for updates), and stepping into mentoring roles. I suggested that we make the semester's research more specific to how the campaign cycle is impacting immigration rhetoric in Nebraska, and our initial brainstorming question flowed into the challenges of collecting enough data specific to campaigns and politicians. We settled on analyzing Nebraska politicians' facebook content on immigration, and the ensuing debates in comment sections. Both returning students were excited to experiment with that source of data, and are already mulling over how they make decisions about what we are looking for an analyzing in those posts. From our early meetings, they were also excited to provide support and ideas to students who were as hesitant and uncertain about the process as they were a semester prior. Two students, a $1^{\text {st }}$ and $2^{\text {nd }}$ year, are joining the team. I will meet with the full team biweekly, and they will meet as a group of 4 on the other weeks, with the two returning scholars leading and directing those meetings.

\section{Future Plans}

I intend for this experiment to scale so that several projects are running each semester. Students will propose or join research projects that serve to expand information available about migration politics in Nebraska, and work collaboratively with other students and myself. Scholars' research tasks will be scaffolded according to their research experience; new scholars (1st and 2nd year students) will collect data, organize preliminary research, and prepare summary outlines, while more experienced scholars will 
train new scholars on conducting research, prepare working drafts, prepare dissemination materials (grant, conference, publication drafts), provide feedback on the work of new scholars, and draft new projects. Each semester will end with a poster session, during which students will present their collaborative or individual research.

\section{Student Learning Outcomes}

How do students self-report their learning in this experience? Below, are students' explanations of their learning during the Fall 2019 semester. Perhaps more than I expected, all students fore fronted their reflections on their learning by noting their hesitations about their preparation to conduct research; one noted "I had never done any research project on this level before, and I was intimidated at first but I wanted to force myself to dive in and see how well I could handle it." And indeed, many of our first meetings focused on linking what skills I knew they had that qualified them for the experience.

First, students reported that this experience brought life to conversations they were having in research methodology courses. One student reported:

The actual application of research methods during this process was so helpful to understand how things operate in the real political science research world. You can read a million journals and argue about a million theories but until you have a question and hypothesis you care about and have to find a defensible way to study it, you just can't quite understand the process.

Another specifically described:

I learned a lot about case selection so I think through how data is collected, how we are being consistent in what we are using for data and where are we getting it, why the significance of using data from certain timelines are in comparison to another set of timelines, and how much data we were collecting. I did not know to ask these questions, and these were also the same questions I was starting to learn to ask in the research methods courses and having a direct application of what that looked like helped in understanding the importance of the research methods classes as well. Each was enrolled in a political science methodology course while participating in the collaborative research, and they each reported that they gained more from the class by engaging with the concepts outside of class, and more from the research experience by being simultaneously enrolled in the class.

Second, students reported that the collaborative research facilitated learning that was very different from their learning in classes. In meetings, students often asked for 
answers to both research decisions and outcomes. While I offered deadlines and stages of the research process, I left the content and methodology of the research open to discussion. Students reflected on the underlying uncertainty of the research process by stating:

I think the fact that it was sort of an experimental process was very helpful for me because I learned how to navigate the process on my own a little bit without the usual structure and guidelines that I usually gravitate towards, which gave me a better understanding of the research process and the different choices you have to make based on the kind of research you want to do.

Students also reported that this uncertainty prompted more creativity and

experimentation, both in their thinking and skill development. One reported:

I also gained more confidence in my writing and much of that had to do with the mentoring and in learning to share 'ugly' drafts. Personally, this was a huge improvement because I do not like sharing incomplete work and this pushed me to do something outside of my comfort zone. For classes, I am only conditioned to turn in the papers I want graded so this was a different experience particularly to have other students also see my not so great writing.

While a syllabus provides a clear trajectory, assessment standards, and timelines, students found the lack of a syllabus to be initially unsettling but opened space for experimentation.

Students also commented on unexpected learning through the process of conducting collaborative research. Specifically, they commented on the benefits of learning through group work and presentation (revealing my own teaching biases, two of the learning processes I have spent the most time to develop into valuable learning activities). One, representative of other comments, reported:

The area I made the most gains was learning to work in a group. I am not a big fan of group project and this research experience required a lot of group work even though many parts of the research were individual. Although we took on individual tasks to write different portions of the paper, without the conversations from our weekly meetings, it would have been difficult to write a cohesive paper. ... This experience made me think so positively of group work. This was also the first time I have ever written anything in such length as a group, but being able to do this together was one of the best parts about the research experience as we were able to rely on each other's strengths.

Others shared similar comments about the experience of presenting at an academic conference, noting "I learned a lot from the conference that we attended through watching other presentations and listening to the feedback and questions that other intellectuals contributed to our research, which was really valuable and unexpected" and "I did not 
realize that I would be so intrigued by presenting our data to others and explaining why we did what we did and how it can be used." While students who joined into this experiment were high-achieving students who often contribute more than they benefit from group work and peer critique, this value of this process was new and exciting.

Finally, students reflected thoughtfully on how the experience allowed them to both experiment with and narrow their professional development plans. One shared:

Thinking about grad school as the future plan, I really wanted to understand what research would be, and it felt like a great way to learn and experience that in a non-scary way because it meant I did not have to wait until senior seminar to either confirm or rethink about my career path."

Another realized that they were better suited for a different portion of work in politics, reporting "Although this was a great experience, it did teach me that I don't think research in the academic capacity is for me. It is super interesting and I loved learning about the topic but at the end I was more interested in policy solutions." Another shared:

I liked thinking about the 'so what' and the implications of the public opinion we analyzed. This helps me think about what I am interested in and showed me that while I enjoy the research, I want to pursue a career that takes it a step further and figures out what to do about addressing the implications that research presents.

Like in other areas, the format of the non-structured, non-graded research experience provided a space for students to experiment and explore; crucially, this allows for earlier exploration of their professional interests.

\section{Lessons Learned}

These student-reported learning outcomes are both encouraging and unexpected. For those interested in experimenting with the model, I document below the biggest decisions that structured and facilitated these outcomes.

What topic and method?

One of the first challenges of this project was selecting a topic that students would be interested in, studied through methods that a range of students would be able to engage with. This is also structured by the decision of how collaborative the research would be; at NWU, students could collect quantitative data, but many do not have the statistical skills to analyze that data, and I wanted students to be exposed to the full research process. And while my own research is on Latin American governance, few students have the language 
skills (even fewer when considering that many that do are upper level students who are studying abroad and heavily involved on campus). I chose to address these challenges by making the research local and proximate to students' lives, drawing on some of my prior work on teaching diversity and social justice (Bauer and Clancy 2018). Most students at NWU are from Nebraska, and those who are not quickly reflect on how quickly they get a primer in and develop a fascination for Nebraska life. Immigration politics was a convergence of my research interests, albeit in a different place, and frequent community conversation.

This thought process required that I identify the core puzzles that motivate my research agenda, stripped from the context where I usually study those questions. Then, I reflected on how students might already be curious about those questions based on their experiences in their own lives and communities, and how a research experience could invite those students (and the people they talk about their research with) to think critically about conversations are inherent or inevitable, and use research to interrogate those assumptions. I also wanted to pick a project that, while part of a broader research agenda, could be 'completed' during one semester so that students had exposure to the full research process (including polishing a paper to meet journal format requirements). I also wanted to ensure that the project had a public-facing outcome (in the first semester, a conference that encouraged student-faculty participation and presentations) to avoid students' assumptions that research existed within a small, private circle.

\section{Which students?}

This decision was one of the most challenging. While the experiment itself was motivated by an effort to ensure equity in student access to research opportunities, I also knew that I wanted to establish record of success to ensure that students who do commit to the research will be part of a well-established project with well-established expectations and outcomes. For the first semester, I chose to focus on developing success and expertise among students, hoping that by expending less energy at the beginning by working with students I knew would excel with the opportunity, I would be able to spend less energy in future semesters as the scope of the project expanded. By starting with a small group of students who had excelled in classes with me, I also hoped that those students would 
develop their own research interests, and get excited about mentoring and serving in leadership roles in future projects.

The second semester, I emailed an application to all majors in the department, as well as a few colleagues in other department in the humanities and social sciences who might know students interested in the work. I also asked students who participated first semester to talk to friends who might be interested, and to be honest as students approached them to inquire about the process. Certainly, this method of diffusion is much more effective on a small campus, but it was effective in giving younger students the confidence to think more about their ambition than their preparation.

\section{What institutional structure?}

As an experimental project, I ran the first and second semesters independent of any institutional structure and without compensation (although I have applied for grants based on the experience). Students had the option to enroll in independent study credit, depending on their existing course load. I attempted to keep many best practices of course management despite not working through that structure. We had a shared google drive, where we kept a list of assignments and meeting agenda per meeting, shared pdfs, uploaded and commented on each other's work. In future semesters, I would like to run the experience through a course, ensuring that the work is compensated in my teaching load and to build up a more structured research experience.

\section{Conclusions}

While many students, particularly the high achieving and motivated students who are likely to self-select into an undergraduate research experience, have learned how to excel in classes, evidence from the first semester of a student-faculty collaborative research lab highlights that the experience pushed students' different cognitive levels, in both the content and process of their learning. While the lack of structure was initially challenging, students came to value the how the structure allowed for experimentation, specialization, and individualization that produced powerful learning.

By centering my research with undergraduate students around one topic, I was able to more intentionally and transparently structure research opportunities for a broader range of students, and provide valuable opportunities for students to collaborate with, learn from, and teach students at different stages of their academic career. Certainly, the 
first semester was experimental and selective, but it sets up the opportunity to gradually scale up opportunities to ensure that undergraduate research opportunities are studentcentered.

\section{Works Cited}

Bauer, Kelly, and Kelly Clancy. 2018. "Teaching Race and Social Justice at a Predominantly White Institution." Journal of Political Science Education 14 (1):72-85.

Becker, Megan. 2019. "Importing the Laboratory Model to the Social Sciences: Prospects for Improving Mentoring of Undergraduate Researchers." Journal of Political Science Education:1-13.

Buddie, Amy M, and Courtney L Collins. 2011. "Faculty perceptions of undergraduate research." PURM: Perspectives on Mentoring Undergraduate Researchers 1 (1):1-21.

Cook-Sather, Alison, Catherine Bovill, and Peter Felten. 2014. Engaging students as partners in learning and teaching: A guide for faculty: John Wiley \& Sons.

Ishiyama, John. 2019. "What Kinds of Departments Promote Undergraduate Research in Political Science?" Journal of Political Science Education:1-14.

Ishiyama, John, and Marijke Breuning. 2003. "Does participation in undergraduate research affect political science students?" Politics \& Policy 31 (1):163-180. 